\title{
STUDI KASUS PERAN TENAGA KESEHATAN MASYARAKAT DALAM UPAYA PROMOTIF DAN PREVENTIF DI KABUPATEN TANJAB BARAT PROVINSI JAMBI
}

\section{Case Study On The Role Of Community Health Personnel In Promotive And Preventive Efforts In Tanjab Barat District, Jambi Province}

\author{
Dwi Noerjoedianto, Andy Amir ${ }^{1,2}$ \\ ${ }^{1,2)}$ Dosen Program Studi Ilmu Kesehatan Masyarakat Fakultas Kedokteran dan Ilmu Kesehatan \\ Universitas Jambi
}

\begin{abstract}
ABSTRAK
Tujuan pembangunan kesehatan adalah meningkatkan kesadaran, kemajuan dan kemampuan hidup sehat bagi setiap orang agar terwujud derajat kesehatan masyarakat yang setinggi-tingginya. Salah satu jenis ketenagaan yang sangat dibutuhkan untuk penyelenggaraan pelayanan kesehatan adalah SKM yang mempunyai peran nyata, sehingga layak untuk dikaji melalui studi kasus. Merupakan penelitian kualitatif dengan design studi kasus, berlokasi di Kabupaten Tanjab Barat, dengan populasi seluruh SKM baik itu yang berstatus CPNS, PNS dan tenaga kontrak. Metode pengambilan sampel purposive sampling, variabel penelitian terdiri tenaga SKM, Kompetensi lulusan, peran tenaga SKM, uraian jabatan/tupoksi, upaya promotif dan upaya preventif, Instrumen penelitian pedoman wawancara terbuka, dan FGD. Analisis Data menggunakan pendekatan content analysis. Uraian dan pemahaman terhadap tugas pokok dan fungsi tenaga SKM yang didasarkan keahlian dan pelatihan sudah ada, dalam bentuk peraturan daerah namun pemahaman masih belum optimal. Namun demikian penjabaran dalam melaksanakan tupoksi yang akan berakibat terhadap capaian indikator kinerja. Sehingga perlu peningkatan pengetahuan baik kediklatan maupun peningkatan pendidikan di semua level unit layanan kesehatan. Upaya tersebut bisa berjalan dengan baik jika ada dukungan kebijakan pemerintah Kab. Tanjab Barat dalam mendukung peran tenaga SKM yang tertuang dalam Rencana Strategi dan Rencana Operasional. Sehingga fokus peningkatan kemampuan profesi SKM adalah kemampuan melakukan advokasi kesehatan, dan pemberdayaan masyarakat.
\end{abstract}

Kata Kunci : Tupoksi, Peran SKM, Keahlian, Dukungan Kebijakan, Upaya promotif dan preventif.

\begin{abstract}
The goal of health development is to increase awareness, progress and ability to live a healthy life for everyone in order to realize the highest level of public health. One type of workforce that is urgently needed for the implementation of health services is Bachelor of Public Health which has a real role, so that it is feasible to be studied through case studies. It is a qualitative research with case study design, located in West Tanjung Jabung District, with a population of all Bachelor of Public Health both those with civil servant candidate status, civil servants and contract workers. The purposive sampling method was taken, the research variables consisted of Bachelor of Public Health personnel, graduate competencies, the role of Bachelor of Public Health personnel, job descriptions/autonomy, promotive efforts and preventive efforts, open interview guideline research instruments, and FGD. Data Analysis uses a content analysis approach. Description and understanding of the main tasks and functions of Bachelor of Public Health personnel based on expertise and training already exists, in the form of regional regulations but understanding is still not optimal. However, the elaboration in implementing tupoksi which will result in the achievement of performance indicators. So that it needs to increase the knowledge of both education and improvement of education at all levels of the health service unit. These efforts can work well if there is support from the district government policy. West Tanjab in supporting the role of Bachelor of Public Health personnel contained in the Strategic Plan and Operational Plan. So the focus on improving the ability of the Bachelor of Public Health profession is the ability to conduct health advocacy, and community empowerment.
\end{abstract}

Keywords: Autonomy, Role of SKM, Expertise, Policy Support, Promotive and preventive efforts.

Korespondensi: Dwi Noerjoedianto

Email: masyudi_psik99@yahoo.com 


\section{Latar Belakang}

Dalam UU Nomor 36 tahun 2009 tentang Kesehatan ditetapkan, bahwa tujuan pembangunan kesehatan adalah meningkatkan kesadaran, kemajuan dan kemampuan hidup sehat bagi setiap orang agar terwujud derajat kesehatan masyarakat yang setinggi-tingginya, sebagai investasi ekonomis. Untuk mewujudkan hal tersebut diupayakan bahwa setiap orang harus mendapatkan informasi dan edukasi tentang kesehatan yang seimbang dan bertanggungjawab serta memperoleh pelayanan kesehatan yang meliputi upaya pelayanan kesehatan yang bersifat promotif,preventif, kuratif dan rehabilitatif yang dilaksanakan secara terpadu, menyeluruh dan berkesinambungan (Kemenkes RI, 2013), yang harus dilakukan oleh tenaga kesehatan yang profesional.

Upaya-upaya ini dalam system pelayanan kesehatan dilaksanakan mulai dari pelayanan dasar tingkat pertama yaitu oleh Puskesmas, yang tertuang dalam Permenkes RI Nomor 75 Tahun 2014. Upaya yang dilakukan oleh puskesmas terdiri dari Upaya Kesehatan Masyarakat (UKM) dan Upaya Kesehatan Perseorangan (UKP), dengan lebih mengutamakan upaya promotif dan preventif. Salah satu jenis ketenagaan yang sangat dibutuhkan untuk penyelenggaraan pelayanan kesehatan tingkat pertama adalah SKM, yang memiliki delapan kompetensi.

Masih banyak permasalahan pelayanan kesehatan masyarakat yang sampai saat ini belum mencapai target yang diinginkan sesuai dengan indikator Millenium Development Goals (MDGs) dan Standar Pelayanan Minimal (SPM) yang disusun berdasarkan Renstra dan Renop Kab. Tanjab Barat. Termasuk permasalahan manajemen pelayanan di puskesmas salah satunya baik secara kuantitas dan kualitas tenaga SKM.

Untuk kepentingan tersebut maka Program Studi Kesehatan Masyarakat Fakultas Kedokteran dan Ilmu Kesehatan berkewajiban melakukan kajian dan analisis peran tenaga kesehatan masyarakat dengan studi kasus di Kabupaten Tanjab Barat Propinsi Jambi.

\section{TINJAUAN PUSTAKA}

Pengertian SKM, Ilmu kesehatan masyarakat adalah berbagai kombinasi ilmu, ketrampilan dan keyakinan yang diarahkan untuk memelihara dan memperbaiki kesehatan suatu masyarakat melalui intervensi atau gerakan sosial yang kolektif. Program atau pelayanan kesehatan masyarakat lebih menekankan pada upaya peningkatan kesehatan, upaya pencegahan penyakit dan perlindungan bagi masyarakat banyak dan bukan hanya individual. Perspektif yang digunakan dalam kesehatan masyarakat adalah kelompok atau masyarakat yang menjadi esensi dari ilmu kesehatan masyarakat.

Dalam implementasinya maka ilmu kesehatan masyarakat akan digunakan oleh tenaga kesehatan masyarakat, yaitu setiap orang yang mengabdikan diri secara aktif dalam bidang kesehatan masyarakat serta memiliki pengetahuan dan atau keterampilan melalui pendidikan di bidang kesehatan masyarakat yang memiliki 8 kompetensi.

\section{Kompetensi Tenaga Kesehatan,}

Pendidikan sarjana kesehatan masyarakat adalah jenjang pendidikan akademik tingkat sarjana dengan delapan kompetensi utama, dengan prinsip dasar KKNI yaitu SKM yang memiliki kemampuan untuk memahami prinsip dasar ilmu kesehatan masyarakat, ketrampilan sebagai pelaksana, serta kemampuan mempimpin dan bekerja bersama dalam suatu tim. Kompetensi penunjang dan kompetensi lain dikembangkan untuk memenuhi kebutuhan peminatan, kecirian yang spesifik dari perguruan tinggi berdasarkan kebutuhan lokal. untuk melaksanakan pendidikan profesi kesehatan masyarakat bekerjasama dengan organisasi AIPTKMI terdapat 8 Kolegium. Adanya kolegium ini akan berujung pada penjurusan dan peminatan, yaitu keahlian khusus yang dimiliki oleh SKM. Kolegium yang dimaksud adalah kolegium epidemiologi, kesehatan lingkungan, kesehatan dan keselamatan kerja, promosi dan pendidikan kesehatan, administrasi kebijakan kesehatan, gizi masyarakat, Biostatistik / KKB, dan kependudukan, daan kesehatan reproduksi. 
Sarjana Kesehatan Masyarakat memiliki kompetensi yang unggul, seperti yang dijelaskan dalam profil kesehatan masyarakat. Kompetensi unggul Kesehatan Masyarakat meliputi MIRACLE (Manage, Innovator, Role Model, Apprentice, Communitarian, Leader dan Educator). Adapun 8 kompetensi tersebut terdiri : Kemampuan untuk melakukan kajian dan analisa (Analysis and Assessment), Kemampuan untuk mengembangkan kebijakan dan prerencanaan program kesehatan (Policy development and program planning), Kemampuan untuk melakukan komunikasi (Communication skill), Kemampuan untuk memahami budaya local (Cultural competency/local wisdom), Kemampuan untuk melakukan pemberdayaan masyarakat (Community dimensions of practice), Memahami dasar-dasar ilmu kesehatan masyarat (Basic public health sciences), Kemampuan untuk merencanakan dan mengelola sumber dana (Financial planning and management), Kemampuan untuk memimpin dan berfikir sistim (Leadership and systems thinking/total system)

\section{METODE PENELITIAN}

Rancangan penelitian ini adalah penelitian kualitatif dengan design studi kasus, yang berlokasi di Kabupaten Tanjab Barat Propinsi Jambi. Populasi seluruh tenaga Sarjana Kesehatan Masyarakat baik itu yang berstatus CPNS, PNS dan tenaga kontrak. Metode pengambilan sampel dengan cara purposive sampling, variabel penelitian terdiri tenaga Sarjana Kesehatan Masyarakat (SKM) , Kompetensi lulusan, peran tenaga SKM, uraian jabatan / tupoksi, upaya promotif dan upaya preventif, Instrumen penelitian pedoman wawancara terbuka, dan Focus Group Discussion (FGD). Cara pengumpulan data dilakukan sesuai dengan jenis data yang yang diperlukan, baik data primer dan data sekunder. Analisis Data menggunakan pendekatan content analysis.

\section{HASIL DAN PEMBAHASAN}

Uraian dan pemahaman terhadap tugas pokok dan fungsi tenaga SKM yang didasarkan keahlian dan pelatihan yang diikuti. Dari pernyataan beberapa informan dalam kegiatan penelitian ini, hampir sebagian besar menyampaikan bahwa sebenarnya uraian tupoksi sudah ada, baik dalam bentuk peraturan daerah maupun dalam kebijakan yang lain. Hanya saja dalam proses penafsiran masih belum begitu baik tergantung persepsi masing-masing, sehingga jika disimpulkan bahwa upaya yang sudah dilakukan oleh Pemerintah Kabupaten Tanjung Jabung Barat telah membuat kebijakan dalam bentuk Peraturan Daerah tentang tugas pokok dan fungsi di instansi pelayanan kesehatan yang merupakan salah satu dasar dalam melaksanakan tugas sebagai PNS, meskipun masih banyak yang belum mengetahui secara detail tentang tupoksi itu sendiri. Dengan adanya tupoksi, akan lebih memudahkan dalam melaksanakan program yang didasarkan pada target dan sasaran yang sudah ditetapkan di awal tahun, sehingga capaian pelaksanaan program akan lebih baik. Hal ini merupakan komitmen Pemerintah Kabupaten Tanjab Barat berupaya menekankan pentingnya tupoksi yang merupakan salah satu indikator keberhasilan bagi capaian program terutama dalam menetapkan target dan sasaran, sehingga hasil pelaksanaan program akan menjadi lebih baik di masa yang akan datang. Hal ini sesuai dengan Kebijakan Kementerian Kesehatan dengan diterbitkannya Permenkes RI Nomor 43 tahun 2016 tentang Standard Pelayanan Minimal Bidang Kesehatan (SPM-BK), yang harus dilaksanakan oleh Pemerintah Kabupaten / Kota di Indonesia.

Dalam melaksanakan kebijakan tersebut harus didukung dengan peningkatan pengetahuan baik secara kediklatan maupun peningkatan pendidikan di semua level unit layanan kesehatan. Terutama dalam kegiatan teknis terhadap permasalahan kesehatan yang ditemukan di lapangan, misalnya pelatihan yang di ikuti yang berhubungan dengan tupoksi masing-masing yaitu : sanitasi RS, limbah B3, pengelolaan air limbah, akreditasi puskesmas, jabfung promkes, analisis beban kerja, akupreseur, fasilitator kader posyandu, TOT desa siaga, GIS, profil kesehatan dan 
pembiayaan kesehatan berbasis JKN. Upaya Pemerintah Kabupaten Tanjung Jabung Barat melalui Dinas Kesehatan Kabupaten Tanjab Barat berkomitmen untuk memberikan peningkatan pengetahuan dan ketrampilan terhadap petugasnya melalui kegiatan diklat, training, dan workshop yang mendukung tupoksi sesuai dengan kompetensi masingmasing. Hal ini sesuai dengan hasil kebijakan Kementerian Kesehatan yang tertuang dalam Permenkes RI No.49 tahun 2016 tentang Pedoman Teknis Pengorganisasian Dinas Kesehatan Propinsi dan Kabupaten / Kota.

Secara spesifik juga dikemukakan penguasaan keilmuan dalam bidang IT, promosi kesehatan, manajemen / ahli perencanaan, pengelolaan keuangan, komunikasi publik, advokasi dan pemberdayaan masyarakat guna mendukung tingkat perkembangan kesehatan di masa yang akan datang. Pada tatanan kebijakan diharapkan peningkatan keahlian profesi SKM yang harus dimiliki meliputi seluruh aspek komponen manajemen, mulai dari perencanaan, pelaksanaan, dan keuangan termasuk dalam optimalisasi IT melalui beberapa kegiatan advokasi dan pemberdayaan masyarakat dengan dukungan komunikasi publik. Keahlian yang harus dimiliki oleh tenaga sarjana kesehatan masyarakat terhadap perkembangan permasalahan kesehatan untuk bekerja di unit layanan kesehatan dan instansi pemerintah lainnya. Kemampuan keahlian yang diharapkan mendukung bagi profesi kesehatan masyarakat adalah perencanaan, administrasi, advokasi kesehatan, iptek, GIS, kesling, kesehatan dan keselamatan kerja, analisis dan olah data, ilmu komunikasi masyarakat, dan teknologi tepat guna. Hal ini yang idealnya dilakukan oleh Pemerintah Kabupaten Tanjab Barat untuk memfasilitasi para tenaga SKM dalam menyongsong perkembangan permasalahan kesehatan masyarakat, sehingga perannya akan lebih berarti dan mempunyai andil bagi peningkatan derajad kesehatan masyarakat. Hal ini sesuai dengan penelitian tracer study yang dilakukan oleh Ahmad Syafiq dkk(2006), yang menyatakan bahwa perlunya kemampuan pengetahuan umum dan penguasaan bahasa inggris, ketrampilan komunikasi baik menggunakan internet, presentasi audiovisual dan alat komunikasi lain selain kemampuan personal dan fleksibilitas motivasi.

Sedangkan keahlian yang harus dimiliki agar dapat berkarya di unit SKPD lain adalah dalam tatanan konsep Ilmu manajemen, yang diawali dari tahap perencanaan, pelaksanaan dan evaluasi yang ditunjang kemampuan komunikasi yang baik, serta dukungan lobby yang berkualitas. Hal ini juga sesuai dengan pendapat Teichler (1999) yang menyatakan bahwa terjadi pergeseran anggapan bahwa pendidikan tinggi mempersiapkan seseorang untuk bekerja menjadi mempersiapkan seseorang untuk hidup yang lebih baik. Didukung oleh kompetensi yang digariskan AIPTKMI bahwa dalam mencetak tenaga sarjana kesehatan masyarakat diharapkan mencapai 8 kompetensi utama diantaranya kemampuan untuk melakukan kajian dan analisa, dan kemampuan untuk mengembangkan kebijakan dan perencanaan program kesehatan. Penelitian lain yang mendukung dilakukan oleh Artha Budi Susila Duarsa yang menyatakan bahwa prospes pendidikan sarjana kesehatan masyarakat bukan hanya di bidang kesehatan saja, melainkan profesi administrator, konsultan, pendidikan, dan advocacy.

Dukungan kebijakan pemerintah Kab. Tanjab Barat dalam mendukung peran tenaga SKM dalam bentuk regulasi, wujud nyata masih belum terpola dengan baik, termasuk penempatan di unit layanan kesehatan, sehingga dukungan untuk pengadaan tenaga kontrak juga belum ada, diharapkan para SKM mengawal pada Renstra yang ditetapkan dengan Perda. Pemerintah Kabupaten Tanjab Barat masih belum menunjukkan dukungan terhadap arah kebijakan yang berpihak kepada para SKM, hal ini dimungkinkan karena belum tahunya tentang kualitas dari tenaga SKM, sehingga harapannya adalah tenaga SKM dalam berkiprah harus masuk dalam agenda penyusunan Renstra yang nantinya akan di tuangkan dalam Perda Kab. Tanjab Barat, sehingga mulai dari desain pengadaan 
CPNS, penempatan termasuk pengadaan tenaga kontrak akan terfasilitasi dengan baik.

Pemerintah Kab. Tanjab Barat masih belum membuat suatu kebijakan dalam bentuk regulasi khususnya tenaga SKM, sehingga perlu pemahaman dan kerjasama lintas sektoral guna mendukung pengakuan tenaga SKM. Hal ini sesuai dengan penelitian Tri Rini Puji Lestari (2014 ) dalam Peran UU Tenaga Kesehatan dan tantangan masalah kesehatan di Indonesia, yang menyatakan perlunya dukungan dalam bentuk kebijakan perlindungan seluruh tenaga kesehatan dalam memberikan pelayanan kesehatan, seiring dengan (1) meningkatnya kebutuhan masyarakat pada pelayanan kesehatan yang bermutu, (2) beban ganda penyakit, dimana angka kesakitan penyakit infeksi masih tinggi, tetapi sebaliknya penyakit tidak menular mengalami peningkatan secara bermakna, (3) disparitas status kesehatan antar wilayah, (4) peningkatan kebutuhan distribusi obat yang bermutu dan terjangkau, (5) jumlah sumber daya manusia yang terbatasdan tidak terdistribusi secara merata, (6) potensi masalah kesehatan akibat bencana dan perubahan iklim, (7) belum terintegrasinya pembangunan infrastruktur kesehatan yang melibatkan lintas sektor di lingkungan pemerintahan pusat daerah dan swasta.

Peningkatan kemampuan profesi SKM yang perlu ditingkatkan dalam upaya promotif dan preventif sesuai dengan keahlian dalam menyongsong perubahan perkembangan permasalahan kesehatan di masyarakat, dengan menitik beratkan kepada kemampuan melakukan advokasi kesehatan, pemberdayaan masyarakat, dengan menggunakan komunikasi yang baik sehingga memiliki kemampuan analisis masalah berdasar kemampuan manajemen organisasi, yang dituangkan dalam manajemen puskesmas, baik itu melalui pendidikan dan pelatihan. Sedangkan peran tenaga SKM khususnya dalam upaya promotif dan preventif yang sudah dilakukan dalam bentuk kebijakan Pemerintah Kabupaten Tanjab Barat dengan mengusulkan anggaran yang berfokus pada kegiatan penggerakan dan pemberdayaan masyarakat serta advokasi kesehatan. Kegiatan secara operasional tertuang dalam Konsep Rencana Strategis dan Rencana Operasional yang berdasarkan Kebijakan Umum Pemerintah Kabupaten Tanjab Barat. Kementerian Kesehatan RI telah menerbitkan Permenkes Nomor 75 tahun 2014 tentang Puskesmas yang mendasari secara detail tugas SKM yang merupakan bagian dari tenaga kesehatan secara umum. Hal ini juga didukung oleh kompetensi dari lulusan sarjana kesehatan masyarakat dari AIPTKMI bahwa harus memiliki kemampuan untuk melakukan pemberdayaan masyarakat dan kemampuan untuk melakukan komunikasi dengan baik.

\section{KESIMPULAN DAN SARAN KESIMPULAN}

1. Uraian dan pemahaman terhadap tugas pokok dan fungsi tenaga sarjana kesehatan masyarakat yang didasarkan keahlian dan pelatihan sudah ada dalam bentuk peraturan daerah, namun pemahaman masih belum menunjukkan persepsi yang sama di semua level unit layanan kesehatan.

2. Keahlian yang harus dimiliki oleh tenaga SKM terhadap perkembangan permasalahan kesehatan di semua lini layanan kesehatan/ instansi pemerintah lainnya adalah perencanaan, administrasi, advokasi kesehatan, iptek, GIS, kesling, kesehatan dan keselamatan kerja, analisis dan olah data, ilmu komunikasi masyarakat, dan teknologi tepat guna.

3. Dukungan kebijakan pemerintah Kab. Tanjab Barat dalam mendukung peran tenaga SKM dalam bentuk regulasi yang dituangkan dalam Rencana Strategi dan Rencana Operasional.

4. Peningkatan kemampuan profesi SKM yang perlu ditingkatkan dalam upaya promotif dan preventif adalah kemampuan melakukan advokasi kesehatan, pemberdayaan masyarakat, yang disampaikan dengan teknik dan metode komunikasi yang baik.

\section{SARAN}

Peran sarjana kesehatan masyarakat harus dibuktikan dengan target indikator dan kinerja sehingga akan berdampak pada peningkatan 
derajad kesehatan di semua lini layanan kesehatan melalui teamwork.

\section{DAFTAR PUSTAKA}

1. Ahmad Syafiq dan Sandra Fikawati, Tracer Study : Melacak Jejak Lulusan FKM Universitas Indonesia ( Hasil Study Kualitatif Tracer Sarjana Kesehatan Masyarakat FKM UI, 2006 ).

2. Artha Budi Susila Duarsa 2009, Prospek Pendidikan Program Pasca Sarjana Bidang Kesehatan Masyarakat, Jurnal Kesehatan Masyarakat,September 2008 Maret 2009 Vol. 3 No.1.

3. Peraturan Menteri Kesehatan Nomor. 75 Tahun 2014 tentang Puskesmas.

4. Peraturan Menteri Kesehatan Nomor. 43 Tahun 2016 tentang Standard Pelayanan Minimal Bidang Kesehatan.

5. Peraturan Menteri Kesehatan Nomor. 44 Tahun 2016 tentang Pedoman Manajemen Puskesmas.

6. Peraturan Menteri Kesehatan Nomor. 49 Tahun 2016 tentang Pedoman Teknis Pengorganisasian Dinas Kesehatan Propinsi dan Kabupaten / Kota

7. Tri Rini Puji Lestari, Peran UU Nakes dan Tantangan masalah kesehatan di Indonesia, Jurnal Kesejahteraan Sosial Vol VI, No.18/II/P3DI/September/2014.
8. Kementerian Kesehatan RI, 2013. Modul Pelatihan Pengangkatan Fungsional Penyuluh Kesehatan Masyarakat (PKM) Terampil. Pusat Promosi KesehatanPuslitbang Aparatur, 2013, Jakarta.

9. Kementerian Kesehatan RI, 2015. Rencana Strategis Pembangunan Kesehatan 2015 - 2019, Jakarta.

10. Universitas Udayana (2007). Petunjuk Pelaksanaan Tracer Studi. BPMU Bali 2007.

11. Kemenristek Dikti RI (2016). Panduan Penelitian dan Pengabdian Kepada Masyarakat di Perguruan Tinggi. Edisi X tahun 2016.

12. Sugiono, 2013. Penelitian Kualitatif . Jakarta

13. Kementerian Kesehatan RI. Badan Pusat Statistik RI, 2012. Survey Demografi dan Kependudukan Indonesia (SDKI) tahun 2012, Jakarta

14. Ikatan Ahli Kesehatan Masyarakat Indonesia (IAKMI), AIPTKMI (2015). Blue Print Kompetensi Sarjana Kesehatan Masyarakat. Jakarta 2016.

15. Teicher U, 1999, Research on the relationship between highher education and the world of work, past achievements, problems and new challenges, higher education, vol 38, : 169- 190. 